ISSN 0103-9954

\title{
EFEITO DA INTENSIDADE DE DESRAMA NA PRODUÇÃO DE Pinus elliottii Engelm., IMPLANTADO EM SOLO POBRE, NO ESTADO DO RIO GRANDE DO SUL
}

\section{THE EFFECT OF PRUNING INTENSITY ON THE PRODUCTION OF Pinus elliottii Engelm., IN A POOR SOIL IN THE STATE OF RIO GRANDE DO SUL}

\author{
Paulo Renato Schneider ${ }^{1}$ César Augusto G. Finger ${ }^{2} \quad$ Juarez Martins Hoppe $^{3}$
}

\begin{abstract}
RESUMO
No presente trabalho estudou-se a influência da intensidade de desrama sobre a produção de madeira de Pinus elliottii Engelm. em um experimento em blocos casualizados com três repetições e 5 tratamentos, definidos por: T1 - testemunha, sem desrama; T2 - desrama dos ramos seco; T3 desrama de $40 \%$ da altura total; T4 - desrama de $50 \%$ da altura total; e T5 - desrama de $60 \%$ da altura total das árvores. Observou-se que o diâmetro e a produção de madeira foram fortemente influenciados pela intensidade da desrama, aos 11 anos de idade. A testemunha com $263,5 \mathrm{~m}^{3} / \mathrm{ha}$ não diferiu do tratamento com desrama de ramos secos com $245,1 \mathrm{~m}^{3} /$ ha, mas ambos diferiram dos tratamentos com desrama de $40 \%$ da altura total com $231,5 \mathrm{~m}^{3} / \mathrm{ha}$, da desrama de $50 \%$ da altura total com 225,5 $\mathrm{m}^{3} / \mathrm{ha}$, da desrama com $60 \%$ da altura total com $211,6 \mathrm{~m}^{3} / \mathrm{ha}$. A menor perda de produção foi de $12,1 \%$ obtida no tratamento com desrama de $40 \%$ da altura total, e a maior de $19,7 \%$ ocorreu no tratamento de desrama com $60 \%$ da altura total. Estes resultados permitem concluir pela recomendação da utilização de desrama com intensidade inferior a $40 \%$ da altura total das árvores, pois permitem menores perdas de produção, ganhos em incremento diamétrico e na qualidade da madeira.
\end{abstract}

Palavras-chave: Pinus elliottii Engelm., desrama, produção.

\begin{abstract}
The effect of the pruning intensity on the production of Pinus elliottii Engelm. was studied in a randomized block design trial with 5 treatments and 3 repetitions. The treatments were: T1 control, without pruning; T2 - pruning of the dead branches; T3 - pruning of $40 \%$ of the total height; T4 - pruning of 50\% of the total height; and T5 - pruning of $60 \%$ of the total height. The diameter and wood volume were affected by the pruning intensity of the 11-year old stand. The control $\left(263.5 \mathrm{~m}^{3} / \mathrm{ha}\right)$ and pruning of the dead branches $\left(245.1 \mathrm{~m}^{3} / \mathrm{ha}\right)$ were different from all other treatments (pruning of $40 \%-231.5 \mathrm{~m}^{3} / \mathrm{ha}$; pruning of $50 \%-225.5 \mathrm{~m}^{3} / \mathrm{ha}$; and pruning of $60 \%-$
\end{abstract}

1. Engenheiro Florestal, Dr., Professor Titular do Departamento de Ciências Florestais. Centro de Ciências Rurais. Universidade Federal de Santa Maria. CEP: 97105-900. Santa Maria. RS.

2. Engenheiro Florestal, Dr., Professor Adjunto do Departamento de Ciências Florestais. Centro de Ciências Rurais. Universidade Federal de Santa Maria. CEP: 97105-900. Santa Maria. RS.

3. Engenheiro Florestal, M.Sc., Professor Adjunto do Departamento de Ciências Florestais. Centro de Ciências Rurais. Universidade Federal de Santa Maria. CEP: 97105-900. Santa Maria. RS. 
$211.6 \mathrm{~m}^{3} / \mathrm{ha}$ ). The smallest production loss was $12 \%$ on the $40 \%$ pruning, and the greatest loss was $20 \%$ on the $60 \%$ pruning treatment. It is concluded that pruning intensities below $40 \%$ of the total height should be employed because of the lower production losses, and increases in diameter and quality of the wood.

Key words: Pinus elliottii Engelm., pruning, yield.

\section{INTRODUÇÃO}

Um povoamento florestal conduzido em espaçamento reduzido, estimula a desrama natural, tendo como consequiência o aumento da qualidade de madeira pela formação de madeira sem nós. Entretanto este processo é lento. Na maioria das espécies, os galhos mortos permanecem por longo período aderidos ao tronco, fator desfavorável à qualidade do lenho dada a inclusão no tronco de grande parte da ramificação lateral, vindo a formar os nós mortos, negros ou soltadiços.

A elevada densidade de árvores em um povoamento concorre para o favorecimento da desrama, mas ocasiona uma diminuição do crescimento em diâmetro das árvores, o que pode ser, de acordo com o objetivo do manejo, desfavorável à condução do povoamento. A desrama artificial e o desbaste surgem então, como meios para conciliar a necessidade de produzir árvores com diâmetros convenientes e com lenho de maior qualidade.

Uma árvore cresce muito bem sem desrama, podendo alcançar o mesmo incremento quando sofrer desrama dentro de parâmetros adequados. Por outro lado, desrama muito intensa afeta o incremento em volume e em diâmetro proporcionalmente a sua intensidade.

A presença de nós vivos ou mortos além de prejudicar a qualidade da madeira, reduz sua resistência, leva a uma classificação comercial inferior e a um preço menor.

A maioria dos defeitos na madeira e em seus produtos podem ser explicados em função das suas propriedades físicas e mecânicas. Assim, por exemplo, a ocorrência de empenamentos pode ser resultado do crescimento desuniforme da árvore, pela combinação na mesma peça de madeira de baixa densidade e alta compressibilidade com lenho mais estável de alta densidade. Isto faz com que o crescimento desuniforme seja altamente indesejável tanto do ponto de vista do desdobro como no de acabamento.

O valor e a utilidade da madeira de povoamentos não manejados são reduzidos, mais pelos nós e pelas distorções da grã do que por qualquer outro fator. Os galhos, depois de findarem sua atividade fisiológica, raramente caem, pois sua presença não constitui uma desvantagem particular para a sobrevivência da árvore. Assim, a desrama artificial é realizada com o intuito de aumentar a qualidade do produto final, obtendo-se madeira limpa em partes do tronco que, de outra forma, só produziriam material de classes de qualidade inferior.

Num programa de desrama, o interesse maior é produzir uma camada externa de madeira livre dos nós. Isto está diretamente relacionado com o tamanho do núcleo nodoso e pode ser controlado pela intensidade, idade do início e pela frequiência da desrama. O fator que assume maior importância é a dimensão do fuste no início da desrama, e deve ser controlado pelo diâmetro do 
núcleo nodoso que se deseja. Porém, há certos inconvenientes em se começar uma desrama cedo demais, pois desramas prematuras significam alturas curtas desramadas e, operações mais freqüentes devem ser realizadas até atingir o comprimento final desejado. Há que considerar também, que a desrama é uma operação dispendiosa e, como investimento efetuados no início da rotação, está sujeita a juros, enquanto os benefícios serão atingidos no futuro, através de preços mais elevados pela madeira livre de nós.

Ao optar por um programa de desrama, é preciso analisar criteriosamente os objetivos, os encargos e benefícios advindos da melhoria da madeira, sem o que se corre o risco de prejuízos, quando não houver a compensação econômica pela produção de madeira de qualidade no corte final. Devido a isto, se torna importante definir critérios que estabeleçam a altura de desrama adequada para cada espécie, região e tipo de povoamento, sem que haja perda no crescimento da floresta, bem como perda econômica.

Em função disto, foi desenvolvido o presente trabalho com os seguintes objetivos:
a) determinar o crescimento em diâmetro das árvores em diferentes intensidades de desrama;
b) definir a intensidade adequada de desrama;
c) verificar o efeito da intensidade da desrama sobre a produção volumétrica.

\section{REVISÃo BIBLIOGRÁFICA}

O objetivo da desrama é produzir madeira de melhor qualidade, livre de nós, facilitar o acesso às marcações de desbaste, reduzir os riscos de danos causados pelo fogo e diminuir os custos de exploração. Em povoamentos manejados para obter grandes diâmetros é necessário ter copas relativamente grandes, o que em conseqüência implica em maior quantidade e tamanhos de ramos, resultando em maior números de nós na madeira (SCHNEIDER, 1993).

Por outro lado, o objetivo usual da desrama em plantações florestais é melhorar as propriedades físicas da madeira serrada, mediante a redução da quantidade e tamanho de nós, através da eliminação de nós mortos ou soltos (AARON, 1969).

Assim, a desrama constitui-se num dos meios mais importantes para valorizar a produção florestal, não existindo outro método, seja biológico ou genético, onde técnicas silviculturais sejam capazes de alcançar o mesmo êxito no aumento do valor comercial e da qualidade da madeira (KNIGGE \& OLISCHAGER, 1970).

De acordo com KRAMER \& KOZLOWSKI (1972), o corte dos ramos vivos reduz a superfície fotossintética, embora reduza também a de respiração. A retirada dos ramos inferiores, que consomem muito produto fotossintético na respiração e pouco contribuem na fotossíntese, permite um ganho na relação produção e consumo de assimilados.

A copa viva da árvore define a posição em que as auxinas e carboidratos são produzidos, sendo que a presença e relativa abundância desses materiais tem forte influência na extensão do lenho juvenil, na proporção de lenho primaveril e outonal e na posição no tronco onde ocorre a 
máxima largura de anel (definindo o afilamento do tronco). A proporção de copa viva pode ser controlada diretamente pela poda, prática estreitamente relacionada com a qualidade da madeira. A taxa de crescimento pode ser aumentada pela seleção de espécies, seleção genética, espaçamento, fertilização e irrigação, quando viáveis. Os efeitos da maior taxa de crescimento, geralmente incluem uma diminuição no comprimento dos traqueídeos e fibras, nas percentagens de celulose, lenho outonal e na densidade, podendo ocorrer aumento nas percentagens de lignina, largura dos anéis de crescimento, volume e lenho primaveril, levando a uma menor densidade da madeira (DANIEL, 1979).

Young \& Kremer apud KREMER \& KOZLOWSKI (1972) observaram, em Pinus taeda L., uma acentuada redução no engrossamento do fuste das árvores com o aumento da intensidade da desrama, porém, não relatam influência desta prática sobre o crescimento em altura e produção.

BERENHAUSER (1970 ) estudou o efeito da desrama sobre o incremento médio anual em altura e diâmetro, e constatou que a mesma produz uma diminuição do incremento das árvores e que as mesmas em pleno estágio de crescimento não toleram a redução exagerada da sua copa viva. $\mathrm{O}$ corte dos galhos ou sua morte em virtude do fechamento do dossel do povoamento, em proporção superior a $50 \%$ da copa viva, representa um verdadeiro sacrifício às partes vitais das árvores, trazendo perdas significativas de crescimento.

Segundo FISHWICK (1977) as pesquisas têm demonstrado que $30 \%$ da copa viva pode ser removida em uma poda programada, sem redução do incremento em volume das árvores. Por outro lado, DANIEL et al. (1982) afirmam que ao podar árvores não se deve eliminar mais de $50 \%$ da copa viva de uma só vez, porque intensidades de poda acima deste percentual afetam negativamente a taxa de crescimento potencial das árvores. A redução da proporção de copa viva mesmo inferior a $50 \%$ põe, quase sempre, as árvores em desvantagem de competição já que o crescimento em altura e diâmetro reduz-se temporariamente. Por outro lado, segundo SCHULTZ (1977), até 66 \% do valor total da árvore está localizado nos primeiros 6 metros de altura, assim sendo, a desrama em maior altura traz apenas uma valorização da madeira, sem acréscimo significativo de valor econômico.

A influência da remoção de galhos vivos na produção de madeira e na redução da forma do fuste, é inversa ao efeito do desbaste. $\mathrm{O}$ desbaste do povoamento estimula o crescimento do câmbio na base das árvores, enquanto a desrama tende a inibir o crescimento nesta posição, concentrando-o na parte superior do tronco. Assim, a desrama tende a reduzir a forma do tronco, cuja intensidade de redução depende da severidade da mesma. As desramas entre 30 a $40 \%$ da altura total das árvores são consideradas como a de melhor intensidade porém, remoções maiores levam a diminuição da produção de madeira (KOZLOWSKI et al., 1990).

O critério básico para determinar o tamanho e a idade das árvores para desrama está relacionado com o vigor de crescimento, com as condições fisiológicas e econômicas vindo a determinar o núcleo enodado desejado (HAWLEY \& SMITH, 1972).

A desrama deve ser realizada ainda quando os ramos estiverem verdes, fazendo com que o nó fique persistente na madeira, o que não acontece com os nós resultantes da poda de galhos secos. Quando se pretende um cerne nodoso pequeno é necessário podar em duas ou três etapas, para 
evitar o corte excessivo da copa viva, o que aumenta o custo da poda de um dado comprimento de tronco (ASSMANN, 1970).

Segundo RAMOS (1973), no manejo de Pinus sp. na África do Sul são utilizadas desramas observando o seguinte programa: a $1^{a}$ é feita quando a altura das árvores dominantes atingem 6,1 metros, sendo desramadas todas as árvores até a altura de 1,8 metros; na $2^{\mathrm{a}}$, são desramadas as melhores 750 árvores/ha, até uma altura de 4,5 metros, quando as árvores dominantes atingirem 9,0 metros; e, na $3^{\mathrm{a}}$, quando as árvores dominantes alcançam altura entre 12,2 a 13,7 metros, são desramadas as melhores 150 árvores/ha, até 6,6 metros da altura do tronco.

Por outro lado, desramas até 12 metros, para árvores com 18,9 metros de altura, realizadas em uma única operação, são muito drásticas, e causam uma diminuição temporária no crescimento em diâmetro, devido a isto, LAAR, (1965) recomenda o uso de duas podas para atingir essa altura.

\section{MATERIAL E MÉTODOS}

\section{Caracterização da área e do povoamento}

A floresta onde foi instalado o experimento, está situada na localidade de Cordilheira, Serra do Piquiri, no extremo sul do município de Cachoeira do Sul, no Estado do Rio Grande do Sul. Esta área está limitada pelas coordenadas geográficas entre $30^{\circ}$ e $31^{\circ}$ de latitude sul e $52^{\circ}$ e $53^{\circ}$ de longitude oeste. A altitude da região varia entre 100 e $500 \mathrm{~m}$ acima do nível médio do mar.

O clima da região é do tipo $\mathrm{Cfb} / \mathrm{g}$, definido pela temperatura do mês mais quente inferior a 22 ${ }^{\circ} \mathrm{C}$ e a do mês mais frio entre -3 a $18{ }^{\circ} \mathrm{C}$.

As precipitações ocorrem durante todos os meses do ano, sendo junho o mês mais chuvoso e dezembro o menos chuvoso, com $166 \mathrm{~mm}$ e $94 \mathrm{~mm}$, respectivamente. A precipitação média anual está em torno de 1606 mm (MORENO, 1961).

O solo da área experimental faz parte da unidade de mapeamento Pinheiro Machado. Tratase de solos litólicos, de baixa fertilidade, bem drenados, coloração escura, textura média, com percentagens elevadas das frações mais grosseiras (areia grossa e cascalhos), tendo como material de origem o granito (LEMOS, 1973).

O material a que se refere este experimento, é constituído de Pinus elliottii E., implantado entre julho e agosto de 1984, numa densidade média inicial de 2000 árvores por hectare.

\section{Delineamento experimental} repetições.

O delineamento experimental utilizado foi o de blocos ao acaso, com 5 tratamentos e 3

Os tratamentos foram definidos pela altura de desrama aplicada, a saber:

Tratamento 1 = T1: testemunha, sem desrama; 
Tratamento $2=\mathrm{T} 2$ : desrama dos ramos seco;

Tratamento 3 = T3: desrama até $40 \%$ da altura total da árvore;

Tratamento $4=\mathrm{T} 4$ : desrama até $50 \%$ da altura total da árvore;

Tratamento 5 = T5: desrama até $60 \%$ da altura total da árvore.

Os tratamentos de desrama foram aplicados até as árvores atingirem 12 metros de fuste desramado. $\mathrm{O}$ corte dos galhos foi feito rente ao tronco, utilizando o serrote de mão.

Como se tratava de experimento de longo prazo foi realizado um desbaste entre $010^{\circ}$ e $11^{\circ}$ ano de idade do povoamento. O peso do desbaste foi determinado pelo índice de espaçamento relativo $(\mathrm{S} \%)$, tendo sido realizado quando este índice atingiu um valor entre 16 e $18 \%$. Com o desbaste, o índice de espaçamento relativo foi elevado para $21 \%$ em todos os tratamentos.

$\mathrm{O}$ índice de espaçamento relativo foi determinado por:

$\mathrm{EM}=\sqrt{ }(10000 / \mathrm{N})$

$\mathrm{S} \%=\mathrm{EM} / \mathrm{h}_{0} \cdot 100$

Sendo: $\mathrm{EM}=$ espaço vital médio em metros; $\mathrm{N}=$ número de árvores por hectare; $\mathrm{H}_{0}=$ altura dominante em metros; $\mathrm{S} \%$ = índice de espaçamento relativo em percentagem.

O número de árvores remanescentes e desbastadas nas parcelas foram determinadas através das fórmulas:

$$
\mathrm{EMD}=\mathrm{S}^{\prime} \% \cdot \mathrm{h}_{0} / 100
$$

$\mathrm{Nd}=\mathrm{N}-\mathrm{Np}$

Sendo: $\mathrm{EMD}$ = espaço médio desejado em metros; $\mathrm{Np}=$ número de árvores a permanecer por hectare; $\mathrm{Nd}=$ número de árvores a desbastar por hectare; $\mathrm{S} \%$ = índice de espaçamento relativo desejado para após o desbaste, definido para os tratamentos, em $21 \%$.

As parcelas tiveram dimensões de $20 \times 20 \mathrm{~m}$, perfazendo $400 \mathrm{~m}^{2}$ de área útil cada e contaram com bordadura intra-blocos de 2 linhas de árvores $(6 \mathrm{~m})$ e bordadura entre blocos com 3 linhas de árvores $(9 \mathrm{~m})$.

As parcelas foram identificadas por placas metálicas, onde foram colocadas informações sobre o experimento, tais como: número do bloco, número da parcela e o tratamento aplicado: testemunha, desrama dos ramos seco, desrama de $40 \%, 60 \%$ e $80 \%$ da altura total das árvores.

Todas as árvores receberam uma faixa pintada ao nível do DAP, local onde foram realizadas as medições de diâmetro. As árvores também foram numeradas seqüencialmente a partir do canto da unidade amostral, com uma placa metálica colocada junto da base da árvore e fixada com prego.

\section{Informações coletadas e análise do experimento}

A idade foi determinada em meses, contados a partir da data de plantio do povoamento, tomada nas informações cadastrais da empresa. 
Nas parcelas foram medidos os DAP (diâmetro a altura do peito), com precisão de décimos de centímetros, de todas as árvores úteis das unidades experimentais. Esta medida foi tomada com fita métrica sob a posição do DAP previamente marcada nas árvores. As alturas de todas as árvores foram medidas com o hipsômetro de Blume-Leiss, com precisão de décimos de metro.

$\mathrm{O}$ experimento foi medido e analisado periodicamente, fornecendo informações sobre o crescimento e a produção da floresta, para cada um dos tratamentos de intensidade de desrama testados.

O volume das árvores foi determinado pela função ajustada com os dados das árvores cubadas pelo método de Smalian, desenvolvida previamente e expressa por:

$\log \mathrm{v}=-4,09524+2,16369 \log \mathrm{d}-0,07597(\log \mathrm{d})^{2}+0,5938 \log \mathrm{h}+0,11352(\log \mathrm{h})^{2}$, sendo: $\mathrm{v}=$ volume $\left(\mathrm{m}^{3}\right) ; \mathrm{d}=$ diâmetro à altura do peito $(\mathrm{cm}) ; \mathrm{h}=$ altura total $(\mathrm{m})$.

As médias dos tratamentos foram comparadas através do Teste de Duncan, ao nível de $5 \%$ de probabilidade.

\section{RESULTADOS E DISCUSSÕES}

Os dados foram avaliados em duas idades do povoamento, 11 anos e 13 anos para a variável volume total com casca por hectare e, aos 13 anos para a comparação da dimensão alcançada pelo diâmetro médio sob diferentes intensidades de desrama.

\section{Volume aos 11 anos}

Na Tabela 1 é apresentada a análise de variância da produção de Pinus elliottii Engelm. sob influência de diferentes intensidades de desrama, obtida aos 11 anos de idade. Observa-se diferença significativa entre os tratamentos testemunha, sem desrama (SD), desrama dos ramos secos (DS), desrama de $40 \%, 50 \%, 60 \%$ da altura total das árvores a uma probabilidade de 0,0080 (Prob.>F), para um valor de F calculado de 7,54. Por outro lado, não foi encontrada diferença significativa entre os blocos, (Prob. $>\mathrm{F}=0,7736$ ), para um valor de $\mathrm{F}$ calculado de 0,27, indicando existência de homogeneidade entre os blocos.

A comparação das médias de volume, através do teste de Duncan, ao nível de $5 \%$ de probabilidade, demonstrou que a testemunha, sem desrama (SD), não diferiu do tratamento com desrama de ramos secos (DS). Porém, ambos os tratamentos diferiram significativamente dos tratamentos com desrama de $40 \%, 50 \%$ e $60 \%$ da altura total das árvores. Por outro lado, os tratamentos com desrama de $40 \%, 50 \%$ e $60 \%$ da altura total não diferiram estatisticamente entre si. Da mesma forma, não diferiram entre si, o tratamento com desrama dos ramos secos do tratamento com desrama de $40 \%$ da altura total das árvores (Veja Tabela 4). 
TABELA 1: Análise de variância da produção de Pinus elliottii Engelm. aos 11 anos de idade.

\begin{tabular}{l|c|c|c|c|c}
\hline Fonte de Variação & GL & SQ & QM & F & Prob.>F \\
\hline Blocos & 2 & 82,4939 & 41,2469 & 0,27 & 0,7736 \\
Tratamentos & 4 & 469,3603 & 1173,3400 & 7,54 & 0,0080 \\
Erro & 8 & 1244,8682 & 155,6085 & & \\
\hline Total & 14 & 6020,7224 & & \\
\hline
\end{tabular}

$\mathrm{GL}$ = graus de liberdade; $\mathrm{SQ}=$ soma dos quadrados; $\mathrm{QM}=$ quadrado médio; $\mathrm{F}$ = valor de $\mathrm{F}$ calculado; Prob. $>\mathrm{F}=$ probabilidade de significância.

Na Figura 1 é apresentada a produção obtida nos tratamentos, aos 11 anos de idade. Observa-se que o maior volume com casca por hectare foi obtido no tratamento sem desrama (SD), com 263,5 $\mathrm{m}^{3} /$ ha, seguido do tratamento com desrama dos ramos secos (DS), com $245,1 \mathrm{~m}^{3} / \mathrm{ha}$. Com desrama de $40 \%$ da altura total das árvores, obteve-se $231,5 \mathrm{~m}^{3} / \mathrm{ha}$, ou seja, uma diferença de volume em relação a testemunha de $12,1 \%$. A produção volumétrica do tratamento com desrama de $50 \%$ da altura total das árvores foi de $225,5 \mathrm{~m}^{3} /$ ha, sendo esta $14,4 \%$ menor que a da testemunha. A menor produção foi obtida no tratamento com desrama de $60 \%$ da altura total das árvores, com 211,6 m²/ha, 19,7\% menor que a da testemunha, sem desrama.

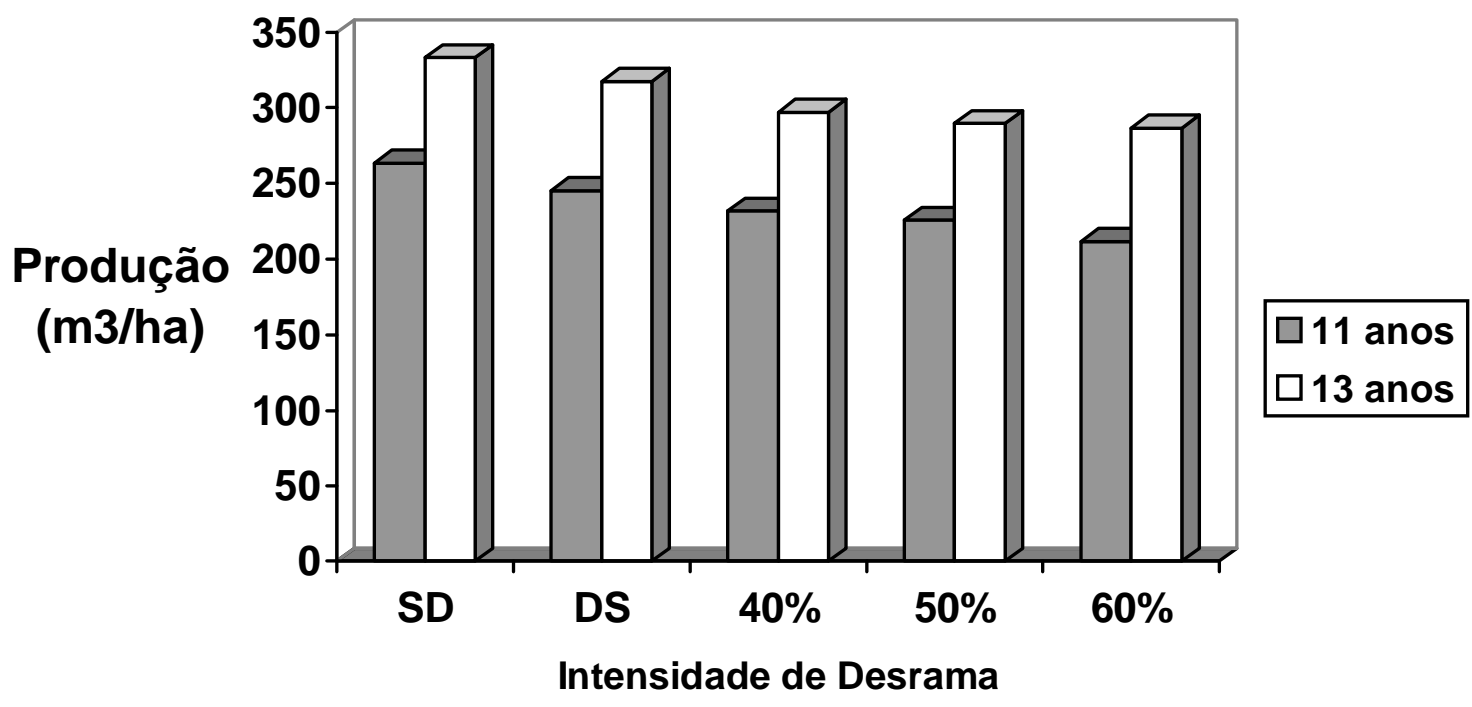

FIGURA 1 : Produção de Pinus elliottii Engelm. com diferentes intensidades de desrama, aos 11 e 13 anos de idade. 


\section{Volume aos 13 anos}

A análise de variância da produção obtida nos tratamentos de diferentes intensidades de desrama, com dados medidos dois anos após a execução do desbaste, é apresenta na Tabela 2. Observa-se que, mesmo aos 13 anos de idade e após a realização do desbaste, manteve-se a diferença significativa entre os tratamentos de desrama, a uma probabilidade de 0,0084 (Prob.>F), e um valor de F calculado de 7,44.

A comparação das médias dos tratamentos pelo teste de Duncan (sob efeito dos desbastes) demonstrou que foi produzido pela testemunha (SD) $333,2 \mathrm{~m}^{3} /$ ha, não diferindo do tratamento com desrama dos ramos secos com $317,6 \mathrm{~m}^{3} / \mathrm{ha}$. Porém, ambos os tratamentos diferiram significativamente dos tratamentos com desrama de $40 \%$ da altura total das árvores $\left(297,1 \mathrm{~m}^{3} / \mathrm{ha}\right)$; de $50 \%\left(289,9 \mathrm{~m}^{3} / \mathrm{ha}\right)$; e de $60 \%$, $\left(286,2 \mathrm{~m}^{3} / \mathrm{ha}\right)$. Por outro lado, estes três tratamentos não diferiram estatisticamente entre si (Veja Tabela 4).

TABELA 2: Análise de variância da produção de Pinus elliottii Engelm. aos 13 anos de idade.

\begin{tabular}{l|c|c|c|c|c}
\hline Fonte de Variação & GL & SQ & QM & F & Prob.>F \\
\hline Blocos & 2 & 447,9888 & 223,9944 & 1,39 & 0,3023 \\
Tratamentos & 4 & 4782,3705 & 1195,5926 & 7,44 & 0,0084 \\
Erro & 8 & 1284,9071 & 160,6133 & & \\
\hline Total & 14 & 6515,2664 &
\end{tabular}

GL = graus de liberdade; $\mathrm{SQ}=$ soma dos quadrados; $\mathrm{QM}=$ quadrado médio; $\mathrm{F}$ = valor de $\mathrm{F}$ calculado;

Prob. $>\mathrm{F}=$ probabilidade de significância.

\section{Diâmetro}

A análise de variância dos diâmetros obtidos nos tratamentos, aos 11 anos de idade, conforme mostra a Tabela 3, demostrou a existência de diferença significativa entre as diferentes intensidades de desrama, a uma probabilidade de 0,0043 (Prob.>F), para um F calculado de 9,23.

TABELA 3 : Análise de variância do diâmetro de Pinus elliottii Engelm., aos 11 anos de idade.

\begin{tabular}{l|c|c|c|c|c}
\hline Fonte de Variação & GL & SQ & QM & F & Prob.>F \\
\hline Blocos & 2 & 0,101333 & 0,050666 & 0,45 & 0,6522 \\
Tratamentos & 4 & 4,149333 & 1,037333 & 9,23 & 0,0043 \\
Erro & 8 & 0,896666 & 0,112333 & & \\
\hline Total & 14 & 5,149333 &
\end{tabular}

$\mathrm{GL}=$ graus de liberdade; $\mathrm{SQ}=$ soma dos quadrados; $\mathrm{QM}=$ quadrado médio; $\mathrm{F}=$ valor de $\mathrm{F}$ calculado; Prob. $>\mathrm{F}=$ probabilidade de significância.

A comparação das médias dos diâmetros, aos 11 anos de idade, feita com o teste de Duncan, ao nível de $5 \%$ de probabilidade, demonstrou que a testemunha, sem desrama, não diferiu do tratamento com desrama dos ramos secos, mas diferiu dos demais tratamentos com $40 \%, 50 \%$ e 60 $\%$ da altura total desramada, porém estes não diferiram entre si. Por outro lado, o tratamento com desrama seca não diferiu do tratamento com desrama de $40 \%$ da altura total (Veja Tabela 4). 
Na Figura 2 é apresentado os valores dos diâmetros médios, obtidos na testemunha, sem desrama (SD), e nos tratamentos com desrama dos ramos seco (DS) e nos tratamentos com desrama de $40 \%, 50 \%$ e $60 \%$ da altura total das árvores. Observa-se que, em um período de 4 anos, contados a partir do estabelecimento das desramas no povoamento florestal, ocorreu uma diferença de $1,17 \mathrm{~cm}$ entre o diâmetro médio da testemunha, sem desrama, e o diâmetro médio do tratamento com desrama mais severa, ou seja de $60 \%$ da altura total das árvores. Deve-se considerar ainda que, os tratamentos foram desbastados de forma equânime aos 11 anos de idade não tendo havido mudanças nas tendências observadas antes e depois do desbaste como comprovam estes resultados.

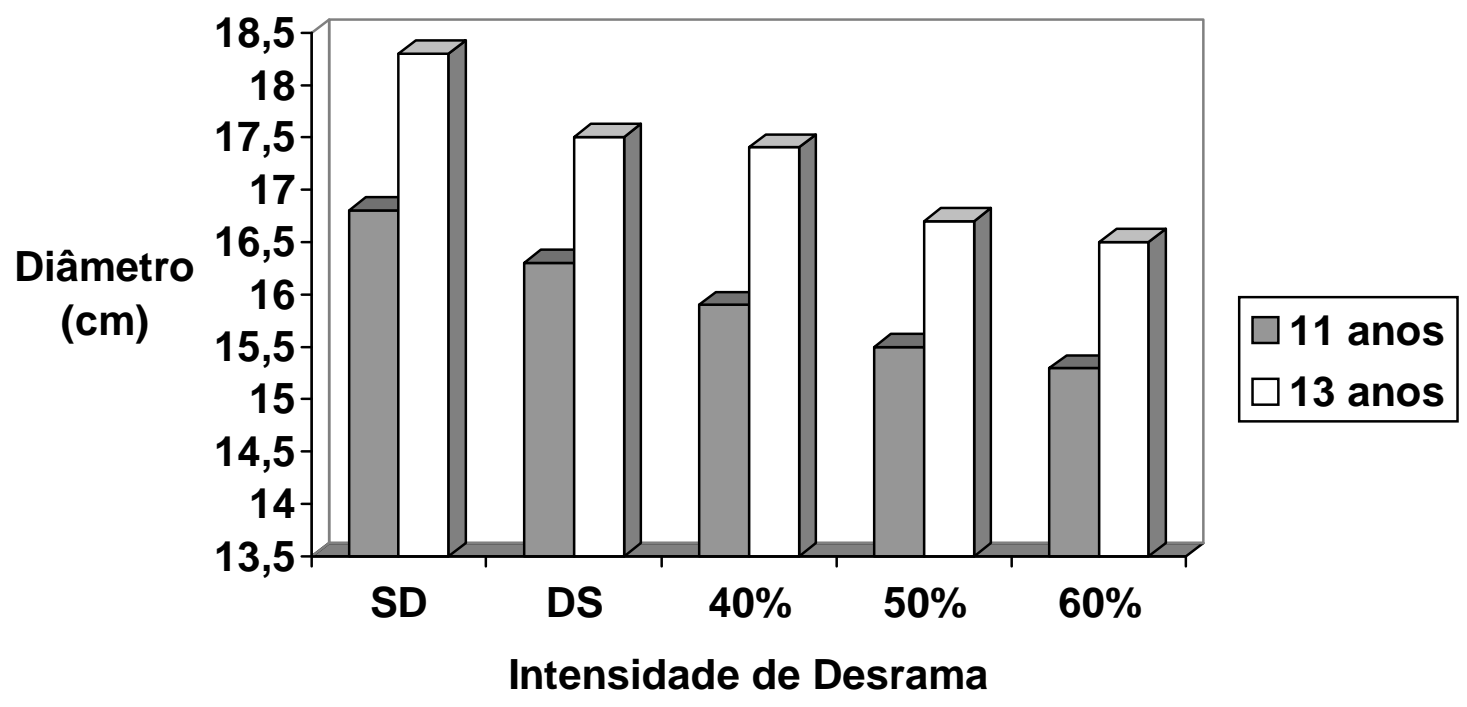

FIGURA 2 : Diâmetro médio de Pinus elliottii Engelm. sob diferentes intensidades de desrama, aos 11 e 13 anos de idade.

$\mathrm{Na}$ Tabela 4 é apresentada uma síntese dos parâmetros dendrométricos obtidos nos tratamentos testados, como o diâmetro médio, volume atual por hectare, volume do desbaste por hectare, produção total por hectare e o incremento médio anual (IMA), em metros cúbicos por hectare por ano, aos 11 anos de idade, bem como a comparação das médias pelo teste Duncan, ao nível de $5 \%$ de probabilidade.

O incremento médio anual do diâmetro nos tratamentos testados mostraram as mesmas tendências verificadas para o volume, ou seja a sua redução com o aumento da intensidade de desrama. O maior incremento encontrado, nesta idade, foi $23,9 \mathrm{~m}^{3} / \mathrm{ha} / \mathrm{ano}$, obtido na testemunha, sem desrama, e o menor, de $19,2 \mathrm{~m}^{3} / \mathrm{ha} / \mathrm{ano}$, ocorreu no tratamento com desrama de $60 \%$ da altura total das árvores. 
TABELA 4: Parâmetros obtidos nos tratamentos de desrama em talhões de Pinus elliottii Engelm., aos 11 e 13 anos de idade.

\begin{tabular}{l|c|c|c|c|c|c}
\hline \multirow{2}{*}{ Tratamentos } & \multicolumn{3}{|c|}{11 ANOS } & \multicolumn{3}{c}{13 ANOS } \\
\cline { 2 - 7 } & $\begin{array}{c}\text { DAP } \\
(\mathrm{cm})\end{array}$ & $\begin{array}{c}\text { Produção } \\
\left(\mathrm{m}^{3} / \mathrm{ha}\right)\end{array}$ & $\begin{array}{c}\text { IMA } \\
\left(\mathrm{m}^{3} / \mathrm{ha} / \mathrm{ano}\right)\end{array}$ & $\begin{array}{c}\text { DAP } \\
(\mathrm{cm})\end{array}$ & $\begin{array}{c}\text { Produção } \\
\left(\mathrm{m}^{3} / \mathrm{ha}\right)\end{array}$ & $\begin{array}{c}\text { IMA } \\
\left(\mathrm{m}^{3} / \mathrm{h} / \mathrm{ano}\right)\end{array}$ \\
\hline $\begin{array}{l}\text { T1:Testemunha sem } \\
\text { desrama }\end{array}$ & $16,8 \mathrm{~A}$ & $263,5 \mathrm{~A}$ & 23,9 & $18,3 \mathrm{~A}$ & $333,2 \mathrm{~A}$ & 25,6 \\
$\begin{array}{l}\text { T2: Desrama dos ramos } \\
\text { seco }\end{array}$ & $16,3 \mathrm{AB}$ & $245,1 \mathrm{~A}$ & 22,2 & $17,4 \mathrm{AB}$ & $317,6 \mathrm{AB}$ & 24,4 \\
T3: $40 \%$ & & & & & & \\
T4: $50 \%$ & $15,9 \mathrm{AC}$ & $231,5 \mathrm{C}$ & 21,0 & $17,4 \mathrm{~B}$ & $297,1 \mathrm{BC}$ & 22,8 \\
T5: $60 \%$ & $15,5 \mathrm{C}$ & $225,5 \mathrm{C}$ & 20,5 & $16,7 \mathrm{C}$ & $289,9 \mathrm{C}$ & 22,3 \\
\hline
\end{tabular}

$\mathrm{DAP}=$ diâmetro à altura do peito; IMA = incremento médio anual.

\section{CONCLUSÕES}

Os resultados obtidos no presente trabalho permitiram concluir que:

a) a produção volumétrica foi influenciada pelas intensidades de desrama, tendo sido encontrada diferença significativa entre os tratamentos, ao nível de $5 \%$ de probabilidade, aos 11 anos e aos 13 anos de idade;

b) a testemunha, sem desrama, não diferiu do tratamento de desrama seca, porém ambos diferiram dos tratamentos com desrama de $40 \%, 50 \%$ e $60 \%$ da altura total das árvores; estes não diferindo entre si, aos 11 anos de idade;

c) a testemunha, sem desrama apresentou maior produção, com $263,5 \mathrm{~m}^{3} / \mathrm{ha}$, seguida do tratamento com desrama seca, com $245,1 \mathrm{~m}^{3} / \mathrm{ha}$, da desrama de $40 \%$ da altura total das árvores, $\operatorname{com} 231,5 \mathrm{~m}^{3} /$ ha, da desrama de $50 \%$ da altura total das árvores com $225,5 \mathrm{~m}^{3} / \mathrm{ha}$, e da desrama de $60 \%$ da altura total das árvores com 211,6 m³/ha, aos 11 anos de idade;

d) a maior perda de produção, $19,7 \%$, em relação a testemunha, sem desrama ocorreu no tratamento com desrama drástica, desrama de $60 \%$ da altura total das árvores;

e) a menor perda de produção, $12,1 \%$ em relação a testemunha, foi verificada no tratamento com desrama de $40 \%$ da altura total das árvores;

f) o crescimento em diâmetro foi severamente afetado pela intensidade de desrama, tendo sido encontrado uma diferença de $1,17 \mathrm{~cm}$, aos 11 anos de idade, entre o diâmetro médio do tratamento sem desrama e o do tratamento com desrama drástica, $60 \%$ da altura total das árvores;

g) para fins práticos as desramas com intensidade inferior a $40 \%$ da altura total das árvores são as mais recomendadas, pois produzem menores perdas de produção, maior diâmetro e uma melhor qualidade da madeira; 
h) mesmo após a aplicação de desbaste de igual intensidade em todos os tratamentos, os resultados mostraram aos 13 anos de idade que, as tendências de crescimento observadas aos 11 anos de idade, tanto para a variável diâmetro como para o volume por hectare, não foram alteradas.

\section{REFERÊNCIAS BIBLIOGRÁFICAS}

AARON, J. R. Pros and cons of pruning in conifers. Journal of Forestry , v.63, n.4, p.295-304, 1969.

ASSMANN, E. The principles of forest yield study. New York: Pergamon Press. 1970. 384p.

BERENHAUSER, H. Importância da poda em Pinus spp. para produção de madeira de melhor qualidade. Rev. Floresta, v.3, n.3, p.33-35, 1970.

DANIEL, T. W. Principles of Silviculture. 2a ${ }^{\mathrm{a}}$ ed. New York: McGraw - Hill, 1979. 410p.

DANIEL, Th, W.; HELMS, J. A. \& BAKER, F. S. Principles de Silvicultura. 2 a ed. México: McGraw - Hill, 1982. 492p.

FISHWICK, R. W. Dados iniciais sobre poda em Pinus elliottii. Brasília: Prodepef, 1977. 7p. (Comunicação Técnica, 5)

HAWLEY, R. C. \& SMUTH, D. M. Silvicutura prática. Barcelana: Ed. Omega S.A., 1972. 544p.

KNIGGE, W. \& OLISCHLAGER, K. Möglichkeiten der Grünastung der Fichte. Holz-Zbl. v.96, p.1497-1500. 1970.

KOZLOWSKI, T. T.; KRAMER, R.J. \& PALLARDY, S.G. The Physiological Ecology of Woody Plants. San Diego, California: Academic Press, 1990. 657p.

KRAMER, J. P. \& KOSWLOSKI, T. Fisiologia das árvores. Lisboa: Fundação Caloustre Gulbekian, 1972.745p.

LAAR, A. Von. High pruning of Pinus radiata. South African Forestry Lourval. v.52, p.27-33, 1965.

LEMOS, R.C.; AZOLIN, M.A.D.; ABRAÃO, P.V.R. \& SANTOS, M.C.L. Levantamento e reconhecimento dos solos do Estado do Rio Grande do Sul. Recife: Ministério da Agricultura, Departamento Nacional de Pesquisas Agropecuárias - Divisão de Pesquisas Pedológicas, 1973. 431p. ( Boletim Técnico, 30).

MORENO, J.A. Clima do Rio Grande de Sul. Porto Alegre: Secretaria da Agricultura-Diretoria de Terras e Colonização, 1961. 42p.

RAMOS, I. África do Sul: horizonte florestal do Brasil. São Paulo: Editora Joruês, 1973. 81p.

SCHNEIDER, P. R. Introdução ao manejo florestal. Santa Maria: CEPEF/FATEC/ UFSM, 1993. $348 \mathrm{P}$.

SCHULTZ, H. Unsere Enkel und IKW Wertholz. Holz-zbl. v.103, p. 741-743, 1977. 